\title{
Mediação não é conciliação. Sobre um legado da obra de Antonio Candido
}

\author{
ALFREDO BOSI ${ }^{I}$
}

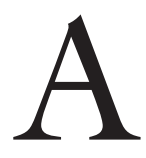

BUSCA de uma chave para a compreensão do método crítico de Antonio Candido traz-me sempre à mente a palavra "mediação". Lendo, porém, certos comentários a respeito das posições políticas e ideológicas dessa figura extraordinária de crítico e militante, vejo que mediação é comparada equivocadamente a conciliação. É preciso aprofundar o significado do conceito para desfazer essa relação indesejada. Primeiro, por via negativa, mostrando que os objetivos do discurso mediador nada têm a ver com os alvos do discurso conciliador. Depois, entendendo mais a fundo os procedimentos da mediação e sua lógica interna.

A conciliação exerce, em geral, a função retórica de aplainar ou mesmo recusar as diferenças que caracterizam lados diferentes ou opostos de uma mesma questão. Com isso tenta-se canhestramente aglutinar possíveis semelhanças, o mais das vezes superficiais, e evita-se enfrentar o sentido interno que anima os interlocutores. A mediação, ao contrário, não cria uma fala eclética e confusa, mas constrói uma terceira linguagem que traduz os significantes de uma posição dando-lhes outra dimensão semântica.

Um primeiro exemplo, tomado do conflito entre formalismo e historicismo, que acompanhou boa parte da trajetória de Antonio Candido como crítico literário e professor de Teoria Literária. No antológico ensaio sobre as Memórias de um sargento de milícias, de Manuel Antônio de Almeida, "Dialética da malandragem", o crítico vale-se de esquemas binários para caracterizar grupos sociais do meio urbano fluminense do "tempo do Rei”. A contraposição é organizada em termos de ordem e desordem, reunindo semelhanças e diferenças entre as personagens que trabalham e as que vivem de expedientes e pequenas espertezas dentro de um clima de irresponsabilidade. Mas, ao adotar um procedimento classificatório, Candido não cede ao caráter estático dos termos, nem lhes dá uma conotação de perenidade, como é próprio dos esquemas estruturalistas, tão em voga entre nós nos anos 60 e 70 do século passado. Ao passar da análise formal da narrativa para a interpretação sociológica, ele faz penetrar uma seiva social que transforma os puros nomes abstratos de ordem e desordem em realidades psicológicas vivas e capazes de mutações surpreendentes. Nesse sentido, a sua ação é a do mediador construindo uma terceira linguagem, que já não é mais 
nominal e estruturalista, mas um transporte de signos verbais para a esfera móvel dos comportamentos individuais condicionados por um certo contexto. A versão ensaística entra em sintonia com as peripécias do romance, a que o crítico atribui "um moto contínuo", como já se lia no título do capítulo sobre as $\mathrm{Me}$ mórias de um sargento de milícias inserto na Formação da literatura brasileira. Não há, portanto uma tentativa de conciliar estruturalismo de cunho linguístico e uma concepção dialética do contexto que acena para uma sociedade de favor com seus apadrinhamentos e parcialidades, envolvendo também os defensores da ordem. Nem por isso Candido generaliza a sua interpretação para toda a história brasileira, como alguns adeptos de um marxismo ortodoxo fariam, rotulando o romance de alegoria da nossa prática social. De resto, a alegorização é, muitas vezes, o descarte das diferenças locais e individuais, que tanto pesam na ficção, em prol de uma também abstrata classificação da matéria narrativa

Um exemplo precoce da prática da mediação encontra-se no belo texto sobre $O$ Conde de Monte Cristo, "Da vingança", que se lê em Tese e antítese. Trata-se de um dos seus primeiros ensaios longos, datando de 1952 a primeira versão. Aqui o conflito se dá entre uma leitura de cunho psicológico e outra, historicista e culturalista. Tampouco o autor busca uma conciliação fácil entre ambas as correntes. $\mathrm{O}$ que a concepção hegemônica nesse começo dos anos 1950 atribuía ao romantismo, como se esse fosse um corpus unitário de temas e motivos, a leitura psicológica tendia a esmiuçar as características existenciais, no caso, passionais, do herói vingador. Candido individualiza a figura de Edmundo-Monte Cristo, aprofunda as suas motivações, dá-lhe uma fisionomia inconfundível sem perder de vista que se trata de um "herói byroniano”. Nesse retrato, há uma síntese vigorosa de cultura romântica levada ao frenesi e o retrato vivo de um homem condenado ao cárcere por uma intriga de desafetos. Em outras palavras, a sua descrição não cede nem à compulsão de tudo explicar por tendências de uma certa cultura em certa época, alvo do historicismo estrito, nem se abandona ao mito da personalidade única, que um abusivo individualismo aplica sempre às personagens centrais do romance ou do drama. A mediação se faz na passagem do geral (o espírito da época) ao particular, a história de um homem traído que se vinga. Nessa tradução, foge-se aos determinismos de uma hipotética ciência da literatura como expressão imediata da sociedade e de uma obsessão biográfica, que aparta o protagonista da experiência do seu tempo. Mais uma vez, o crítico evita alegar correntes teóricas que o discurso conciliador preferia ver aglutinadas. O que, sabemos, é um tento, e não dos menores, se lembrarmos que a divergência entre os historicistas puros e os então chamados críticos estéticos levantava polêmicas nas universidades e nos suplementos literários em toda parte... E os que desejavam conciliar apenas se detinham na tentativa eclética de montar um discurso que se abria com as características gerais dos períodos, atravessando depois vida e obra dos autores, de tal modo que a análise do texto e a sua interpretação ficavam premoldadas desde o início dos textos de crítica. 


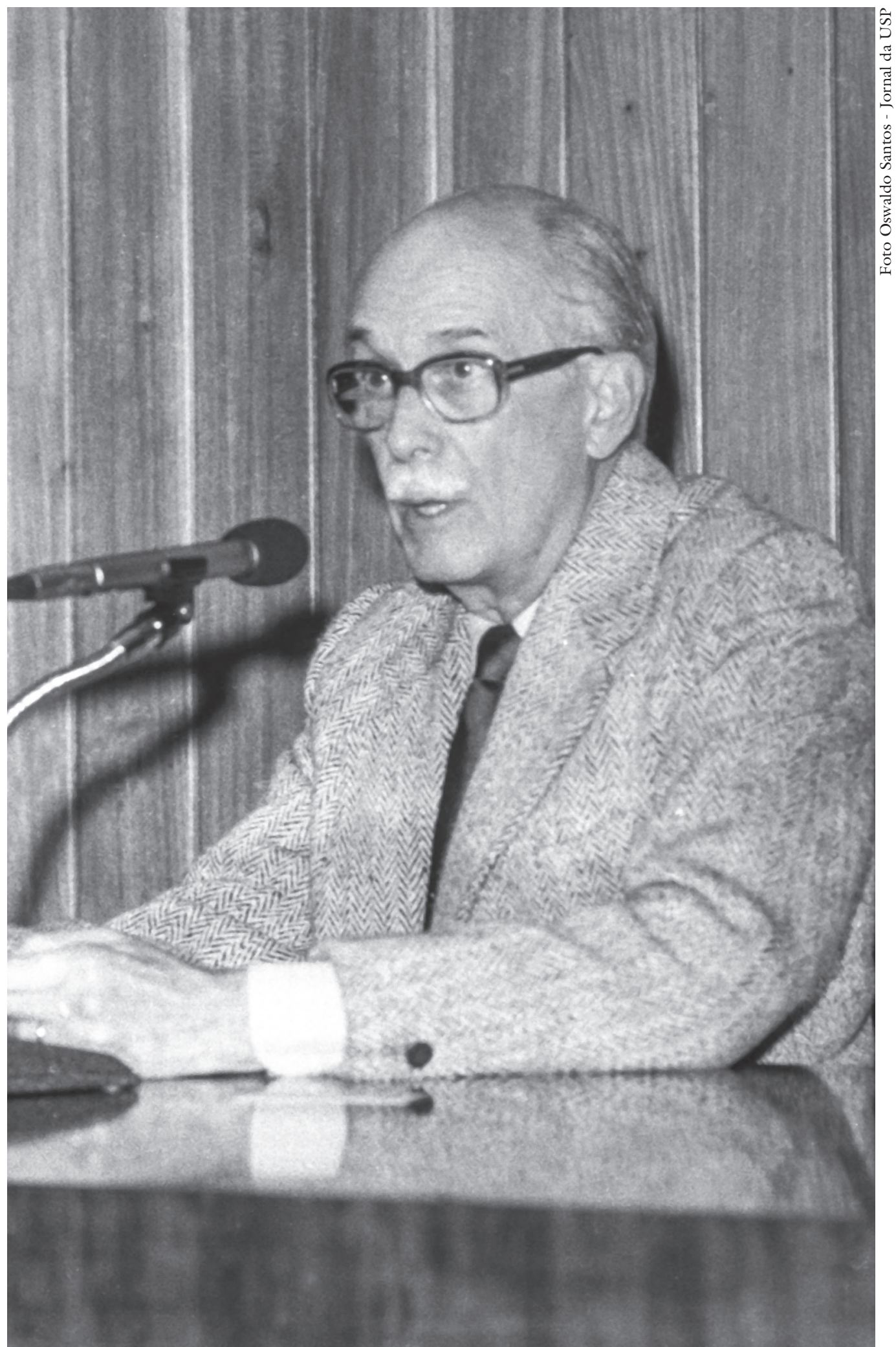

O professor Antonio Candido na USP em 1986. 
Mas o tento maior foi alcançado com a publicação da Formação da literatura brasileira, um livro-matriz dos estudos de história literária, que ainda tem muito a dar e ensinar. A seriação cronológica não deixa de parecer, aos olhos pós-modernos, uma forma mais ou menos explícita de evolucionismo linear. Alguns leitores menos avisados têm criticado o que seria um vezo progressista e teleológico das histórias literárias tradicionais, herdeiras do positivismo do século XIX. A procura de precursores e a caça de influências seriam os procedimentos típicos dessa visão que considera em cada autor e em cada livro o que veio do passado e se transformou em topos retórico e literário. Candido conseguiu, ainda uma vez, sem comparações aleatórias, dar um quadro dinâmico da história do romance brasileiro romântico. Na verdade, há retomada de motivos e temas, o que é evidente quando se considera, por exemplo, a formação do regionalismo romântico e depois realista, que necessariamente se detém em descrições de paisagens e caracterização de tipos locais. Mas também nesse particular, a sua discrição singular evitou atribuições de causalidade externa. Leia-se o capítulo sobre os Três Alencares, em que a trajetória do romancista é analisada por miúdo, ressalvando a originalidade de cada obra e cada personagem relevante. Efeito notável do método crítico de Antonio Candido é o enriquecimento e o adensamento do próprio conceito de romantismo, que, mediante a criação estética dos seus melhores autores, perde o teor de generalidade onipresente que lhe emprestava a leitura externa das suas múltiplas expressões.

Não haveria mãos a medir se intentássemos fazer a análise dos ensaios exemplares de Tese e antitese, Vários escritos e $O$ discurso e a cidade. São viveiros de observações atentas, descobertas insuspeitadas, interpretações agudas e abrangentes. É um olhar que considera a forma e o sentido de texto examinado sem perder a percepção de detalhes, que, a rigor, são pistas valiosas para o intérprete que nada perde do essencial nem do que a outros olhos pode parecer supérfluo: a decoração de uma casa, o gesto furtivo de uma personagem ou a sintonia do clima com o estado de alma do narrador.

Tendo-me dedicado por algum tempo ao estudo da literatura italiana, foi com surpresa e admiração que li "O mundo-provérbio", ensaio sobre a obra-prima de Verga, I Malavoglia. Que me conste, nada há na farta bibliografia italiana sobre esse romance que se compare à complexidade da abordagem de Antonio Candido. O núcleo da interpretação está na reflexão do sentido social e existencial dos provérbios evocados ao longo da narrativa. A palavra-chave é fechamento. Uma comunidade de pescadores sicilianos era, ainda nos fins do século XIX, um lugar cerrado, onde as situações e os comportamentos se repetiam invariavelmente, dado o estado de carência dos moradores da aldeia. Nesse clima de quase imobilidade do tempo os provérbios naturalizavam o caráter fatal dos acontecimentos e das palavras, pensamentos e gestos que compunham o estreito círculo do cotidiano. 
Nesse contexto o grau de determinismo é alto, o que se ajustava como a mão e a luva à proposta de objetividade formulada pelo realismo chamado "verismo" pela crítica italiana do tempo. A perspectiva sociológica reconhece no romance de Verga precisamente esse reflexo da realidade como norte da construção narrativa, no caso aderente à força inexorável de um estilo de vida sem saída. Antonio Candido, como sociólogo de comunidades arcaizantes, autor de Os parceiros do Rio Bonito, estava perfeitamente armado para enfrentar uma interpretação contextual do romance. No entanto, reconheceu na procura de salvação econômica do protagonista um esforço para driblar as forças determinantes da sua carência. Como chefe da família de pescadores, Padron 'Ntoni se endivida junto a um usurário para comprar uma partida de tremoços que seu filho, Bastianazzo, deveria vender aos tripulantes de um navio ancorado no porto. A garantia do empréstimo é sua própria casa. Mas a alternativa do comércio tentada por esse pescador malogra tragicamente com o naufrágio da embarcação que tem por nome Providência. No entanto, 'Ntoni, ao ver o navio partindo, recita para si mesmo um provérbio siciliano que, no caso, parece augurar uma boa fortuna para a viagem com sua carga de tremoço: "Scirocco chiaro e tramontana scura, méttiti in mare senza paura" - "Siroco claro e vento Norte escuro, põe-te ao mar sem medo". O ditado tranquiliza o pescador, mas, como toda abertura, arrisca-se ao fracasso, os caprichos da tempestade desfazem o sonho de escapar da miséria. que sobrevirá inapelável. Candido analisa sutilmente o paradoxo que consiste em invocar um provérbio que corresponde, de fato, ao pensamento desejoso do pescador, mas que, no âmbito de uma sociedade rústica sem saídas, não se realizará. Nas palavras do crítico: "Isto mostra que o provérbio invocado como garantia não passa de desejo angustiado". O ponto de vista sociológico mantém-se e é reforçado pelo esquema de homologias entre a fala rústica e a sociedade rústica. Mas é internamente dialetizado pela análise dos pensamentos e sentimentos do protagonista, que procura no provérbio um conforto possível no meio dos infortúnios que aleatoriamente impedem que a esperança transforme a realidade. Não há, em última análise, tentativa de conciliação entre crítica de fundo sociológico e crença romântica na independência psicológica das personagens. Há, na verdade, um aprofundamento dialético da abordagem contextual que permite pensamentos e sentimentos contrastantes com a força dos fatos e dos fados.

\section{Coerência de um projeto socialista e democrático}

Se na sua longa trajetória de crítico e historiador das Letras Antonio Candido conservou sempre íntegra a sua capacidade de mediação sem ceder a qualquer tipo de ecletismo simplificador, o mesmo se deu, e de modo ainda mais visível, no curso de sua militância política e ideológica.

Nos seus primeiros anos de juventude o Brasil ainda estava sob a égide do Estado Novo. A oposição política, sobretudo de esquerda, vivia na clandestinidade, que se tornou forçosa depois da Intentona comunista. A repressão só começou a abrandar com o final da Segunda Guerra e a vitória das forças aliadas 
contra o nazifascismo, abrindo-se nos meados dos anos 1940 uma brecha para reivindicações democráticas. O Brasil, que voltava do conflito como participante da luta, aspirava ao fim da ditadura com a convocação de eleições e restabelecimento dos partidos. Nesse contexto de esperanças cidadãs um grupo de socialistas independentes aceitou aliar-se com uma agremiação liberal, a União Democrática Nacional, para aparelhar-se politicamente nos termos de uma possível participação eleitoral. Esquerda Democrática foi o nome escolhido como bandeira de união dos descontentes com o regime e, ao mesmo tempo, distanciados do Partido Comunista Brasileiro, então vinculado ao estalinismo. A associação do grupo com a UDN talvez cause estranheza aos que só conheceram esse partido como articulador do golpe de 1964, quando já degenerara em lacerdismo transformando-se em "vivandeira dos quartéis", na feliz expressão de um dos seus mais antigos militantes. Candido aproximou-se de intelectuais do porte de Sérgio Buarque de Holanda, Rubem Braga, Paulo Emílio Salles Gomes, amigo dileto, João Mangabeira, Hermes Lima, José Honório Rodrigues, Evandro Lins e Silva, Paulo Duarte, Azis Simão, José Lins do Rego e tantos outros que mantiveram um projeto de fusão das práticas da democracia representativa com os ideais de justiça social, afastando-se coerentemente do puro centro liberal encarnado pelo udenismo. A Esquerda Democrática carreou água para a criação do Partido Socialista Brasileiro em 1947.

Com seu ingresso na docência universitária, primeiro como assistente de Sociologia, depois como professor de Teoria Literária na USP e na Unicamp, Candido assumiu pelo exercício do magistério a proposta de arejar não só o campo dos estudos humanísticos, como toda e qualquer forma de reacionarismo e preconceito que constatasse em nossa vida intelectual. A sua ação discreta e constante fez-se nas salas de aula e nas páginas de sua obra, influindo eficazmente em um sem número de estudantes e leitores.

Durante a ditadura civil-militar, que seduziu intelectuais ditos liberais e direitistas, a sua presença se fez sentir em círculos diversos, como a Comissão de Justiça e Paz e a Associação dos Docentes da Universidade de São Paulo. Era a palavra justa, que nada concedia ao poder mas perseverava na prática do diálogo com o eventual adversário. Foi o mediador por excelência nas agitadas assembleias que acirravam as posições ideológicas. Na Comissão de Justiça e Paz, criada pelo cardeal Evaristo Arns, procurava dar corpo às esperanças do padre Lebret, amigo duradouro, que vaticinara a união dos socialistas democráticos com os cristãos progressistas como frente anticapitalista. Sem nenhuma crença religiosa, no sentido confessional da expressão, considerava, porém, de valia a missão civilizadora das igrejas quando não fanatizadas por princípios fundamentalistas. Assim pôde fazer, como poucos, uma saudável mediação entre crentes e agnósticos, que coincidiam na luta pela liberdade e pela justiça. Nessa, como em outras esferas, não havia preocupação de conciliar teoricamente posições filosóficas contrastantes. A sua inteligência límpida recusava-se a cair na confusão verbal. 
Animado do mesmo espírito de convivência civilizada, foi com alegria que viu formar-se, no final dos anos 1970, quando a ditadura parecia ter os dias contados, uma frente de luta pelos direitos dos trabalhadores aproximando sindicalistas independentes, cristãos progressistas e intelectuais de uma renovada esquerda democrática. Esse movimento, que cresceu durante as memoráveis greves do $\mathrm{ABC}$, daria origem à criação de um partido singular na história política brasileira, o Partido dos Trabalhadores (PT). Antonio Candido, já entrado na casa dos 60 anos de idade, e reputado como o maior crítico brasileiro de todos os tempos, aderiu de coração ao novo projeto, dando-lhe por anos e anos o seu apoio moral e intelectual. Ficou, de todo modo, distante da rotina partidária, o que the deu margem para pôr-se ao largo das conciliações, na verdade, concessões, que o partido acabou fazendo para subir ao poder e nele manter-se. Candido sabia que os melhores ideais sofrem um processo de entropia quando entram no jogo das forças em que se resume, o mais das vezes, toda a prática política. Mas eram os ideais e os valores que o interessavam e julgava que era absolutamente necessária uma dose de otimismo, pois se dizia um optimista, sempre pronunciado com o $\mathrm{p}$ mudo... O pessimismo paralisa a iniciativa, tolda a consciência com uma nuvem de presságios, e, no caso da política, impede a coragem da iniciativa.

Os amigos, que conviveram com os últimos anos de Antonio Candido, notaram que era com tristeza que falava dos rumos que o próprio PT e seus inimigos ferrenhos estavam dando à política brasileira. Pôde ver o atoleiro onde nos lançaram corruptos e golpistas de todo naipe. Preferia calar. Mas nem por isso, deixou de redigir uma bela carta de apoio à candidatura de Fernando Haddad à reeleição municipal em São Paulo em 2016. Era preciso que a sua esperança encontrasse meios e modos de criar uma linguagem em que a política fosse mediada pela ética. Todos os seus alunos, leitores e amigos lhe somos gratos por esse dom que generosamente nos transmitiu como seu melhor legado.

Alfredo Bosi é professor titular de Literatura Brasileira na Universidade de São Paulo e membro da Academia Brasileira de Letras. Publicou, entre outras obras, História concisa da literatura brasileira; O ser e o tempo da poesia; Céu, inferno; Dialética da colonização; Machado de Assis: o enigma do olhar; Literatura e resistência; Brás Cubas em três versões; Ideologia e contraideologia; e Entre a literatura e a história. É editor da revista Estudos Avançados. @ - abosi@usp.br

Recebido em 24.5.2017 e aceito em 30.5.2017.

${ }^{I}$ Faculdade de Filosofia, Letras e Ciências Humanas, Universidade de São Paulo, São Paulo, São Paulo, Brasil. 